\title{
FOUR IMPLANT SUPPORTED MANDIBULAR OVERDENTURES WITH RIGID TELESCOPIC ATTACHMENTS. A STUDY OF CIRCUMFERENTIAL BONE RESORPTION USING CONE BEAM COMPUTERIZED TOMOGRAPHY
}

\author{
Dina Bahgat El Talawy* and Samer Mostafa Ali**
}

\begin{abstract}
Aim: This study aimed to evaluate circumferential bone resorption around implants supporting mandibular overdentures with rigid telescopic attachments.

Materials and methods: Eight totally edentulous participants with adequate remaining bone mesial and distal to the mental foramen received four implants in canine and first molar areas of the mandible. After 3 months of osseointegration, telescopic attachments were connected to the denture. Marginal bone resorption was measured around canine and molar implants using Cone beam computerized tomography (CBCT) at base line, 6 months $(6 \mathrm{~m})$, and 12 months $(12 \mathrm{~m})$ after overdenture insertion.
\end{abstract}

Results: The survival rate was $97 \%$ after one year. The mean marginal bone resorption at all implant surface combined together is $1.41 \pm .54 \mathrm{~mm}$. Posterior implants were associated with significant higher marginal bone resorption than anterior implants for distal, lingual and mesial surfaces. The highest marginal bone resorption was noted at the lingual surface followed by mesial surface, then distal surface and the lowest marginal bone resorption was noted with buccal surface. For lingual, mesial and buccal implant surfaces of anterior implants, bone resorption at $12 \mathrm{~m}$ was significantly higher than bone loss at $6 \mathrm{~m}$.

Conclusion: Despite the limitation of this study, implants supporting mandibular overdentures with rigid telescopic attachments is a successful treatment option for edentulous mandible. However, this treatment modality is associated with increased bone loss around molar implants compared to canine implants. Also, the lingual implant surface was associated with significant higher bone resorption than other implant surfaces after one year of loading.

KEYWORDS: implant, mandibular, overdentures, telescopic attachments, of bone resorption

* Associate Professor, Department of Removable Prosthodontics, College of Oral and Dental Surgery, Misr University For Science and Technology, Egypt.

** Associate Professor, Department of Removable Prosthodontics, Faculty of Dentistry, Modern Science and Arts University (MSA), Egypt 


\section{INTRODUCTION}

Although the use of 2 implants to provide retention for the mandibular overdentures are satisfactory for majority of unsatisfied edentulous patients with conventional complete dentures ${ }^{1}$. However, this type of prosthesis is supported by the mucosa. The totally implant supported overdentures with 4 implants are mandatory in many cases. Such cases include patients with resorbed mandibular ridges, easily irritable mucosa, dehiscence of mental nerve, knife edge crest of the mandibular ridge, sharp mylohyoid ridge, opposing natural teeth to distribute stresses widely on the mandibular implants and extreme gaggers $^{2}$. The implant supported overdentures have several advantages such as; reduction of mucosal support ${ }^{3}$, excellent retention and stabilization of the prosthesis and minimization of ridge resorption due to elimination of denture rotation and posterior ridge loading ${ }^{4}$. The rigid anchoring of such prosthesis also provide stable occlusion, reduce prosthodontic maintenance ${ }^{5}$, and improves biting force, chewing efficiency and muscle activity compared to 2 implant overdentures ${ }^{6}$. In contrast to fixed prosthesis, implant supported overdentures are cost effective, more hygienic, easy in maintenance, suitable for patients with phonetic-esthetic problems as loss of lip support, long clinical crowns, and great interarch spaces ${ }^{7}$

A common design for implant supported overdentures is installation of 4 interforaminal implants in the mandible and connection of the implants with bar attachments with cantilevered short bar segments to provide adequate support, retention and stability to the overdenture and to minimize mucosal loading during mastication ${ }^{8}$. The high success rate of interforaminal implant is due to high bone density and location away from vital structures ${ }^{10-13}$. Miyamoto et al., ${ }^{14}$ showed that connection of implants distal to the foramen with implants mesial to the foramen with fixed restoration worsens the success rate of posterior implants due to misfit of the long superstructure after casting and mandibular flexture in the posterior region which is harmful to the bone-implant interfaces. Several authors ${ }^{6,15-17}$ demonestrated the insertion of implants distal to the mental foramen to support mandibular overdentures when availabe bone present. Komiyama ${ }^{15}$ noted patient satisfaction with this implant distribution when long bar is used, enhance denture stability and retention. Furthermore, comfort and mastication is enhanced ${ }^{16}$ due to quadrilateral and wide implant distribution ${ }^{18,19}$. Elsyad, et al. ${ }^{6}$ reported that this design enhance masticatory function of mandibular overdentures compared to 2 implant overdentures.

Telescopic attachments are composed of primary (inner) and secondary (outer) crowns. Telescopic attachments may be rigid which include friction between parallel walls, the conical, and the non rigid (resilient) ones. Rigid telescopic crowns direct occlusal contact between inner and outer copings. Retention is gained by friction obtained from the parallel milled surfaces of the inner and outer crowns during insertion and removal. Conical (tapered) telescope crowns exhibit friction only on complete seating using a "wedging effect." 20-22. Telescopic attachments provide several advantages compared to bar attachments such as easier oral hygiene, selfinsertion ability in patients with handling problems, high retention by friction, excellent denture support and stability especially in patients with atrophied ridges, and minimal restriction of tongue space ${ }^{22-24}$

In invitro study, ELsyad, et al. ${ }^{17}$ showed minimal peri-implant strain with rigid telescopic copings when the implants were inserted in canine and first molar region in a quadrilateral design compared to 4 implants inserted in the interforaminal area. They attributed to this result to the favorable load distribution which is similar to a seat with $4 \operatorname{legs}^{25}$. However, the rigid nature of the attachment may transfer high load to the implant during function. Accordingly, the purpose of the current investigation is to evaluate the circumferential bone resorption around 4- implants supporting mandibular overdentures with rigid telescopic attachments. 


\section{MATERIAL AND METHODS}

\section{Participant enrollement}

Eight totally edentulous participants (4 males and 4 females, mean age $=59.48 \pm 4.5$ years) who attend regularly at the clinic of prosthodontic department were enrolled in the current investigation. The inclusion characters are; 1) all participants were unsatisfied by the retention of the old mandibular dentures and wanted a more stable and retentive prosthesis, 2) sufficient remaining bone in height, width mesial and distal to the mental foramen to allow installation of at least $11 \mathrm{~mm}$ implant in length and $3.7 \mathrm{~mm}$ implant in diameter. This was checked by Cone beam computerized radiographic evaluation before implant insertion. 3) adequate amount of interarch space of at least $12 \mathrm{~mm}$ from the occlusal plane of the mandibular denture to the mucosa of the ridge, 4) absence of any systemic and metabolic disorder that may affect osseointegration such as diabetes mellitus and hyperparathyrodism. Exclusion characters include: 1) blood disorders, 2) patients under radiotherapy or chemotherapy, 3) inability to practice good oral hygiene, and 4) uncooperative patients. Patients were coached about the objectives of the proposed treatment protocol and an informed consent was obtained, according to the ethical principles of Helsinki Declaration (https://www.wma.net/).

\section{Surgical and prosthetic protocols}

Forall participants, new upperand lower complete dentures were made using bilateral balanced occlusal concept and semi anatomic acrylic artificial teeth. Duplication of the mandibular denture using clear acrylic resin to produce a radiographic template was performed. Each patient was instructed to wear the template during cone beam radiographic evaluation to evaluate proposed implant sites regarding bone height and thickness, and approximation to vital structures (mandibular canal and mental foramen). Radiographic template was then converted to surgical template by attachment of metal tubes to the template at the region of canine and first molar acrylic teeth using auto polymerized acrylic resin. The tubes are made parallel to each other's in mesiodistal dimension, and attempt was made to make it parallel in buccolingual dimension. If inclination of the implants is unavoidable buccally or lingually due to mandibular concavities, tubes are inclined to the desired direction and the inclination will be compensated later during waxing of telescopic primary copings. A crestal incision was made from second molar to second molar area on the other side and mucoperiosteal flap was reflected. Four implants (Tiologic, Dentaurm, Germany) were inserted in the canine and first molar region using the standardized 2-stage surgical protocol. The flap was closed with interrupted sutures. The mandibular denture was relined and used during the 3 months healing period. After osseointegration, implants were exposed and healing abutments were threaded to the implants.

After 2 weeks of gingival healing around the abutments, Open tray direct impression procedure was started. Custom acrylic tray was constructed with perforations on the implant positions. Long impression posts were threaded to the implants and splinted in patient mouth using a special resin with minimal dimensional changes (Duralay, Reliance Dental MFG Co, Worth, IL, USA) to assure fixation of the impression posts during impression removal. Light consistency rubber base impression was injected around the impression posts and the overall impression was made using putty material (Zhermack®), Badia Polesine, Rovigo, Italy). Implant analogues were attached to the impression posts and the impression was poured using hard stone. On the model, 4 precious metal abutments ((TioLogic, Dentaurum, Germany) were threaded to the implant analogues. The plastic portions of the abutments were waxed and the wax was milled with special burs (which have $0^{\circ}$ inclination) using a milling device (Confident, Bangalore, India) to give the primary (inner) copings $(6 \mathrm{~mm}$ in height and $5 \mathrm{~mm}$ in diameter). The 4 wax patterns were milled to make their circumferential walls parallel to each other's in mesiodistal and buccolingual direction regardless implant inclination. The wax was invested, cast in cobalt chromium alloy ${ }^{26-28}$ 
(Heraenium Pw, Heraeus-Kulzer GmbH, Hanau, Germany) and refined by milling again. The outer copings were waxed over the inner crowns, invested and cast in the same alloy ${ }^{26-28}$. The primary copings were threaded in patients mouth and secondary copings were seated over the primary ones. Using a pressure indicating paste, the mandibular denture was perforated over the primary copings and the secondary copings were picked up to the primary copings using auto-polymerized acrylic resin while the patients closes on the teeth in centric occlusion to obtain optimum passive fit (fig.1). The overdentures were finished and delivered to the patients with strict oral hygiene measures, the occlusion was refined and follow-up visits were scheduled with patients on 3 months regular recalls.

\section{Measurement of circumferential bone loss}

For each participant, Cone beam computerized tomography (i-CAT device; Imaging Sciences Intl) was made at base line, 6 months $(6 \mathrm{~m})$, and 12 months $(12 \mathrm{~m})$ after denture delivery. The acquisition time, voxel size and slice thickness were standardized for all participants. The acquired DICOMs files were stored on a compact disc. For each implant marginal bone resorption was measured at mesial, distal, buccal and lingual surface. Using a curve tool of the software (OnDemand3DApp Software; CyberMed Inc), a curve was drawn to bisect each implant from the occlusal (axial) view. The images were reconstructed by the software cross sectional

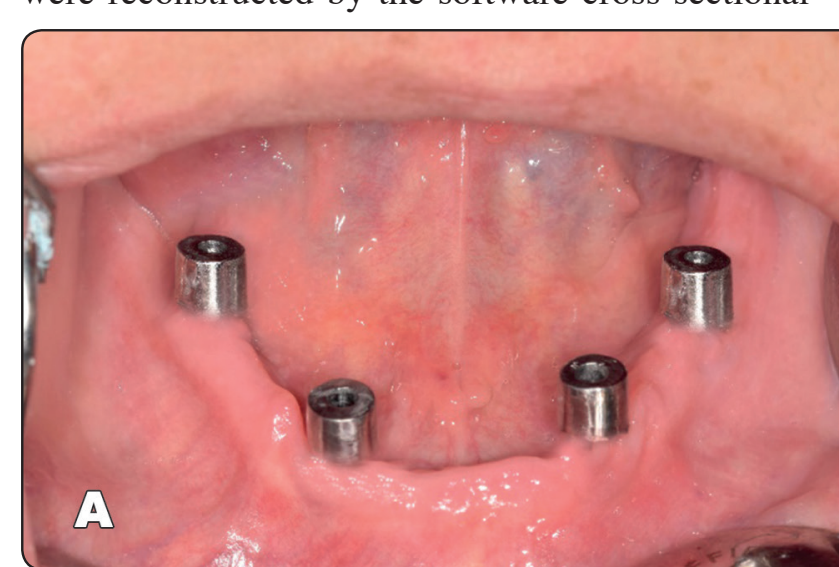

image for each implant and panoramic images for all implants. Mesial and distal peri-implant bone resorption was measured at the panoramic images. Buccal and lingual bone resorption was calculated at cross sectional images (fig.2). To calculate marginal bone resorption, the vertical distance from implant abutment junction (point A) to the bone contact with implant (point B) was measured to give bone level ${ }^{29}$. Bone loss was calculated by subtracting bone levels at $6 \mathrm{~m}$ and $12 \mathrm{~m}$ from bone levels at base line. The bone loss measurement for right and left canine implants were averaged and the mean was considered bone loss for anterior implants. The bone loss measurement for right and left molar implants were averaged and the mean was considered bone loss for posterior implants. To test the inter-examiner validity, 3 different examiners performed the measurement

\section{Statistical analysis}

The Data was analyzed by a computer program (SPSS v25.0; SPSS Inc). the normal distribution of the data was tested by Shapiro Wilk test due to the small sample size. The data were parametric and normally distributed. The inter-examiner validity was tested by $\alpha$ Cronbach test. Two-way repeated measures ANOVA was used to detect significant differences in marginal bone resorption between implant positions (anterior/posterior), implant surfaces (mesial, distal, buccal, and lingual), and time $(6 \mathrm{~m} / 12 \mathrm{~m})$. If significant differences were noted,

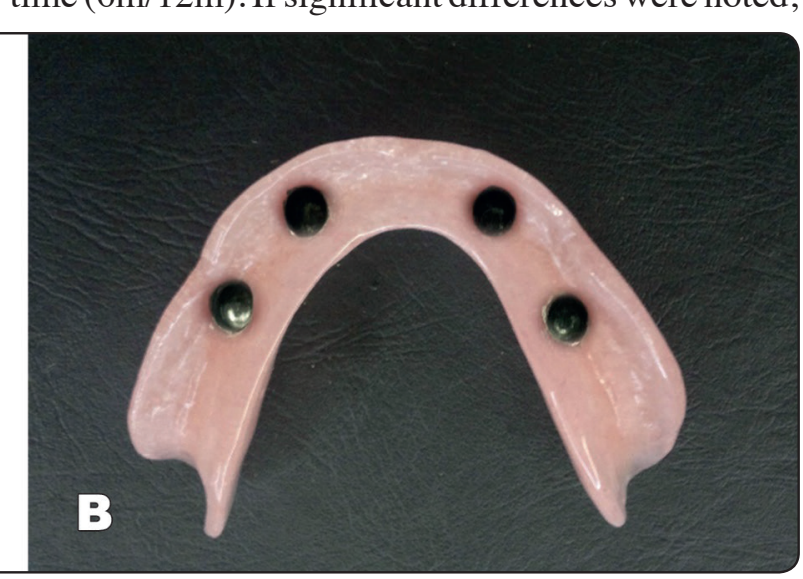

Fig. (1) Telescopic overdenture, A. intraoral view, B. fitting surface of the denture 


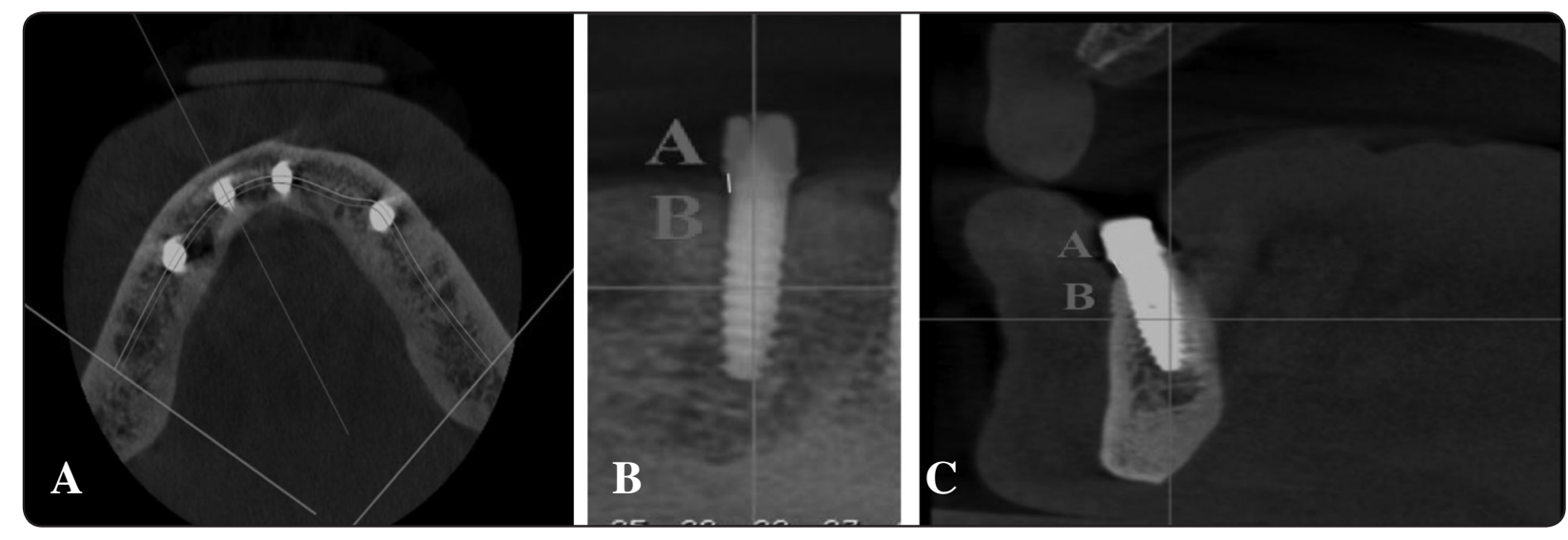

Fig 2: Measurements of marginal bone resorption, A, Axial images with curve tool used to bisect the implants, B, panoramic images, $\mathrm{C}$, Cross sectional images

multiple comparisons were made using Bonferroni test. The level of significance was adjusted at $5 \%$.

\section{RESULTS}

Owing to the short period of evaluation, all participants completed the examinations without dropouts. One implant failed 3 months after loading in molar area result in $97 \%$ survival rate. The failed implant was associated with increased marginal bone loss, mobility and gingival inflammation without suppuration. This implant was removed and excluded from the evaluation. The denture was left to be retained and supported by the other 3 implants after performing adequate relining and adjustment of the occlusion. The data were compared for each examiner using alpha Cronbach test with correlation coefficient $>.80$, therefore the data was considered reliable. The mean marginal bone resorption at all implant surface combined together is $1.41 \pm .54 \mathrm{~mm}$ after one year

Comparison of marginal bone resorption between implant position (anterior and posterior implants) and different implant surfaces (mesial, distal, buccal and lingual surfaces) at $6 \mathrm{~m}$ and $12 \mathrm{~m}$ were presented in table 1 and table 2 respectively. After 6 months (6m) and 12 months (12m), comparison of bone resorption between implant positions showed that posterior implants were associated with significant higher marginal bone resorption than anterior implants for at distal, lingual and mesial surfaces only. However, no difference in bone resorption between anterior and posterior implants was noted for buccal surface.

Comparisons of marginal bone resorption between implant surfaces at $6 \mathrm{~m}$ and $12 \mathrm{~m}$ were presented in table 1 and table 2 respectively. For anterior and posterior implants at $6 \mathrm{~m}$ and $12 \mathrm{~m}$, there was a significant difference in marginal bone resorption between implant surfaces. The highest marginal bone resorption was noted at the lingual surface followed by mesial surface, then distal surface and the lowest marginal bone resorption was noted with buccal surface.

Comparisons of marginal bone resorption between $6 \mathrm{~m}$ and $12 \mathrm{~m}$ for anterior and posterior implants were presented in figure 3 and table 4 respectively. For lingual, mesial and buccal implant surfaces of anterior implants, bone resorption at $12 \mathrm{~m}$ was significantly higher than bone loss at $6 \mathrm{~m}$. However, no difference in bone resorption between $6 \mathrm{~m}$ and $12 \mathrm{~m}$ for distal site was noted. For lingual, mesial and distal implant surfaces of posterior implants, bone resorption at $12 \mathrm{~m}$ was significantly higher than bone loss at $6 \mathrm{~m}$. However, no difference in bone resorption between $6 \mathrm{~m}$ and $12 \mathrm{~m}$ for buccal site was noted. 
TABLE (1) Peri-implant marginal bone resorption for anterior and posterior implants at different surfaces at $6 \mathrm{~m}$

\begin{tabular}{|c|c|c|c|c|c|}
\hline & \multicolumn{2}{|c|}{ Anterior (canine) implant } & \multicolumn{2}{|c|}{ Posterior (molar) implant } & \multirow{2}{*}{$\begin{array}{c}2 \text { way ANOVA } \\
\text { Pvalue }\end{array}$} \\
\hline & Mean & St deviation & Mean & St deviation & \\
\hline Distal & $1.10 \mathrm{a}$ & .17 & $1.47 \mathrm{a}$ & .31 & $.001^{*}$ \\
\hline Lingual & $1.47 \mathrm{~b}$ & .36 & $2.07 \mathrm{~b}$ & .40 & $<.001 *$ \\
\hline Mesial & $1.33 \mathrm{~b}$ & .32 & $1.66 \mathrm{c}$ & .26 & $.003 *$ \\
\hline Buccal & $.91 \mathrm{c}$ & .23 & $.90 \mathrm{~d}$ & .26 & .91 \\
\hline $\begin{array}{c}2 \text { way ANOVA } \\
\text { P value }\end{array}$ & \multicolumn{2}{|c|}{$<.001 *$} & \multicolumn{2}{|c|}{$<.001 *$} & \\
\hline
\end{tabular}

*; $P$ is significant at 5\%, different lower case letters present a significant difference between implant surfaces (Bonferroni test, $P<.05)$.

TABLE (2) Peri-implant marginal bone resorption for anterior and posterior implants at different surfaces at $12 \mathrm{~m}$

\begin{tabular}{|c|c|c|c|c|c|}
\hline & \multicolumn{2}{|c|}{ Anterior (canine) implant } & \multicolumn{2}{|c|}{ Posterior (molar) implant } & \multirow{2}{*}{$\begin{array}{c}2 \text { way ANOVA } \\
\text { P value }\end{array}$} \\
\hline & Mean & St deviation & Mean & St deviation & \\
\hline Distal & $1.13 \mathrm{a}$ & .24 & $1.53 \mathrm{a}$ & .39 & $.003^{*}$ \\
\hline Lingual & $1.55 \mathrm{~b}$ & .47 & $2.18 \mathrm{~b}$ & .40 & $<.001 *$ \\
\hline Mesial & $1.41 \mathrm{~b}$ & .39 & $1.77 \mathrm{c}$ & .30 & $.005 *$ \\
\hline Buccal & $.85 \mathrm{c}$ & .28 & $.90 \mathrm{~d}$ & .30 & .71 \\
\hline $\begin{array}{c}2 \text { way ANOVA } \\
\text { P value }\end{array}$ & \multicolumn{2}{|c|}{$<.001 *$} & \multicolumn{2}{|c|}{$<.001 *$} & \\
\hline
\end{tabular}

*; $P$ is significant at 5\%, different lower case letters present a significant difference between implant surfaces (Bonferroni test, $P<.05)$.

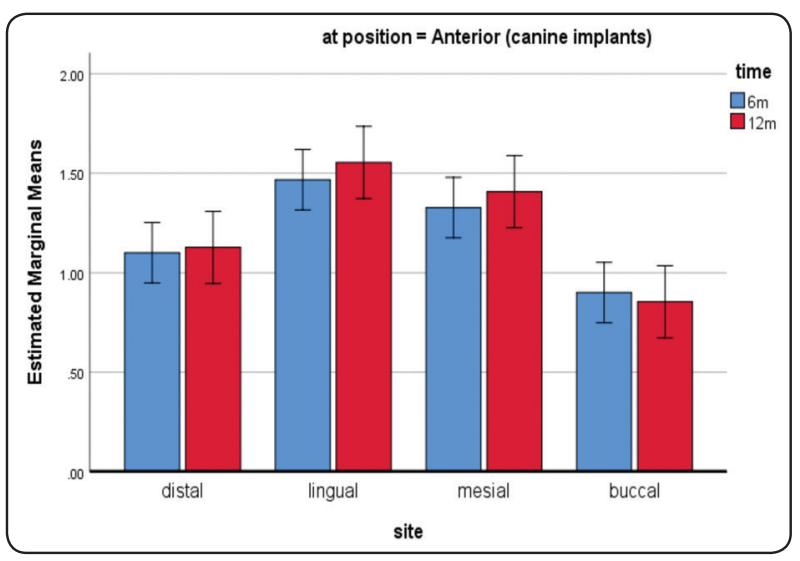

Fig. (3) Comparison of marginal bone resorption between $6 \mathrm{~m}$ and $12 \mathrm{~m}$ for each site for anterior implants. Line connects bars denoted lack of significant difference between time intervals

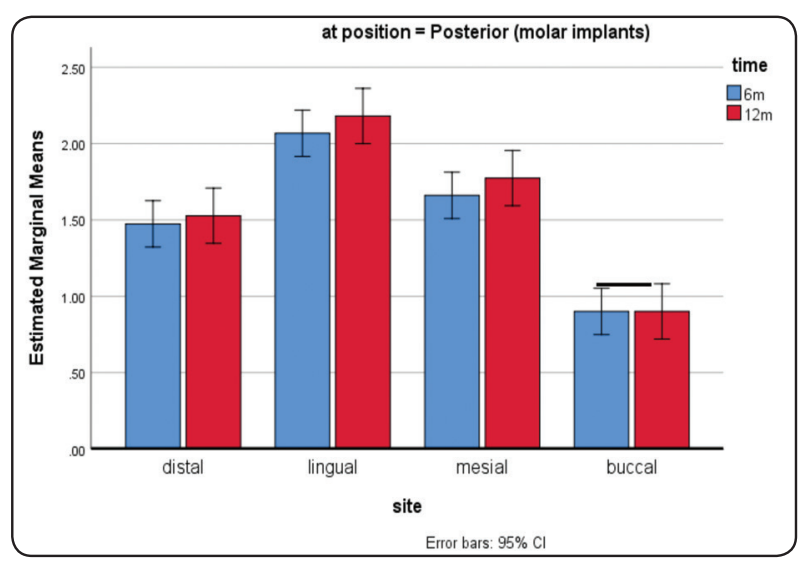

Fig. (4) Comparison of marginal bone resorption between $6 \mathrm{~m}$ and $12 \mathrm{~m}$ for each site for posterior implants. Line connects bars denoted lack of significant difference between time intervals 


\section{DISCUSSION}

In the current investigation Cone beam computerized tomography (CBCT) was used for assessment of marginal bone resorption as it provides information on bone loss on buccal and lingual aspects of the implants as well as mesial and distal aspects due to its three-dimensional nature. In contrast, Periapical radiography are 2 dimensional only. Moreover, CBCT, can be used easily especially elevated floor of the mouth without causing patient discomfort as periapical radiographs do. CBCT also has no magnification or distortion as panoramic radiographs ${ }^{30}$, ${ }^{31}$. The use of CBCT in measuring bone resorption around implants was recommended by other investigators $^{29,32}$. However, the disadvantages of CBCT are increased dose than conventional radiography and metal artefacts although it has minimal effect on measurements. ${ }^{33}$

Reviewing, the literature, there is lack in studies evaluated marginal bone loss around four implant supported overdentures with telescopic attachments especially when posterior implants are inserted distal to mental foramen. The implant survival rate in this study was $97 \%$. In contrast, Krennmair et al. ${ }^{34}$ found a high implant survival/success rate (100\%) for 4 implants inserted in the interforaminal area and supporting mandibular overdenture with rigid telescopic attachments. The slightly reduced survival rate in this study may be attributed to the implant location as the posterior implants were located in first molar region which is associated with the highest occlusal forces in edentulous patient ${ }^{35}$.

The mean marginal bone resorption at all implant surfaces combined together is $1.41 \pm .54 \mathrm{~mm}$ after one year. A similar value of marginal bone loss was observed in a 4-implant supported telescopic crowns $(1.5 \pm 0.8)$ by Krennmair et al. ${ }^{34}$ when the implants were inserted in the interforaminal area using periapical radiographs. The value obtained in this study after one year $(1.41 \pm .54 \mathrm{~mm})$ was higher than normal limit of marginal bone resorption reported in the literature which equal $1.2 \mathrm{~mm}$ during the first year $^{36,37}$. The increased bone resorption could be due to the rigid nature of telescopic attachments which may increase peri-implant stresses under forces of mastication ${ }^{20}$. Moreover, the increased vertical height of the telescopic attachments may constitute a vertical cantilever that can transfer increased stresses around implants that could be responsible for increased bone $\operatorname{loss}^{38}$.

In this study, the bone resorption was significantly higher at $12 \mathrm{~m}$ in the majority of surfaces compared to $6 \mathrm{~m}$. This could be attributed to the increased occlusal load with time and maturation of bone after installation of the implants ${ }^{36}$. Comparison between anterior and posterior implants showed that posterior implants were associated with significant higher marginal bone resorption than anterior ones. This may be attributed to several reasons. Firstly, the high occlusal forced exerted on the implants in the first molar region compared to canine implants may increase stresses around posterior implants and increase bone resorption. In line with this explanation, Tokuhisa et al., ${ }^{35}$ reported that occlusal forces are concentrated around the molar region where the denture would move most. Secondly, the mandibular deformation and flexion posterior to the mental foramen in edentulous patients caused by jaw movements may worsen the prognosis of implants inserts posterior to the foramina after loading ${ }^{14}$. Finally, the bone quantity and quality in posteior mandibular region usually lower than mandibular anterior region. However, no difference in bone resorption between anterior and posterior implants was detected for buccal surface. This could be due to the increased bone density of the labial and cortical plate and the direction of occlusal forces toward the lingual surfaces of the mandible.

The most interesting finding of this study is the highest marginal bone resorption at the lingual surface followed by mesial surface, then distal surface and the lowest marginal bone resorption 
was noted with buccal surface. The increased bone resorption at lingual and mesial surfaces could be attributed to the direction of occlusal forces during biting and mastication which could transmit stresses to the lingual and mesial surfaces of the implants ${ }^{39}$. Moreover, the lingual concavity of the mandible creates a lingual undercuts in the denture flanges which may cause gingival inflamation, stripping, recession and marginal bone resorption in the lingual aspects. Additionaly, the thin lingual cortical plates around the implants contributed to increased bone strain and resorption in the lingual site. In line with this explanation,

The decreased bone loss at buccal aspect could be due to the increased bone density of the labial and buccal cortiical plates as stated previously. In contrast, Elsyad et al. ${ }^{29}$ found that the buccal site were asscoiated with the highest bone resorption. Howerer, Elsyad and colleagues used 2 implant retained overdentures with ball and bar attachments which differs biomechanically from 4 implant supported overdentures utilized in this study.

The small sample size, the short evaluation period, the lack of evaluation of other clinical outcomes, and the lack of control group, are the limitation of this study. Therefore, long term randomized trials with sufficient sample size are still needed.

\section{CONCLUSION:}

Within limitation of this study, implants supporting mandibular overdentures with rigid telescopic attachments is a successful treatment option for edentulous mandible. However, this treatment modality is associated with increased bone loss around molar implants in comparison with canine implants. Also, the lingual implant surface was associated with significant higher bone resorption than other implant surfaces after one year of loading.

\section{REFERENCES}

1. Thomason JM, Feine J, Exley C, Moynihan P, Muller F, Naert I, et al. Mandibular two implant-supported overdentures as the first choice standard of care for edentulous patients--the York Consensus Statement. Br Dent J. 2009;207:185-6

2. Wismeyer D, van Waas MA, Vermeeren JI. Overdentures supported by ITI implants: a 6.5-year evaluation of patient satisfaction and prosthetic aftercare. Int J Oral Maxillofac Implants. 1995;10:744-9.

3. Cordaro L, di Torresanto VM, Petricevic N, Jornet PR, Torsello F. Single unit attachments improve peri-implant soft tissue conditions in mandibular overdentures supported by four implants. Clin Oral Implants Res. 2013;24:536-42.

4. de Jong MH, Wright PS, Meijer HJ, Tymstra N. Posterior mandibular residual ridge resorption in patients with overdentures supported by two or four endosseous implants in a 10-year prospective comparative study. Int J Oral Maxillofac Implants. 2010;25:1168-74.

5. Krennmair G, Krainhofner M, Piehslinger E. The influence of bar design (round versus milled bar) on prosthodontic maintenance of mandibular overdentures supported by 4 implants: a 5-year prospective study. Int J Prosthodont. 2008;21:514-20

6. Elsyad MA, Hegazy SA, Hammouda NI, Al-Tonbary GY, Habib AA. Chewing efficiency and electromyographic activity of masseter muscle with three designs of implantsupported mandibular overdentures. A cross-over study. Clin Oral Implants Res. 2014;25:742-8.

7. Martinez-Lage-Azorin JF, Segura-Andres G, Faus-Lopez J, Agustin-Panadero R. Rehabilitation with implant-supported overdentures in total edentulous patients: A review. J Clin Exp Dent. 2013;5:e267-72.

8. Wismeijer D, Van Waas MA, Vermeeren JI, Mulder J, Kalk W. Patient satisfaction with implant-supported mandibular overdentures. A comparison of three treatment strategies with ITI-dental implants. Int J Oral Maxillofac Surg. 1997;26:263-7.

9. .Abd El-Dayem MA, Assad AS, Abdel-Ghany MM. The effect of different mandibular dentures on antagonistic maxillary ridge. Implant Dent. 2007;16:421-9.

10. Batenburg RH, Meijer HJ, Raghoebar GM, Van Oort RP, Boering G. Mandibular overdentures supported by two Branemark, IMZ or ITI implants. A prospective comparative 
preliminary study: one-year results. Clin Oral Implants Res. 1998;9:374-83.

11. Davis DM, Rogers JO, Packer ME. The extent of maintenance required by implant-retained mandibular overdentures: a 3-year report. Int J Oral Maxillofac Implants. 1996;11:767-74.

12. Mericske-Stern R. Clinical evaluation of overdenture restorations supported by osseointegrated titanium implants: a retrospective study. Int $\mathrm{J}$ Oral Maxillofac Implants. 1990;5:375-83.

13. Naert I, Quirynen M, Theuniers G, van Steenberghe D. Prosthetic aspects of osseointegrated fixtures supporting overdentures. A 4-year report. J Prosthet Dent. 1991;65:671-80.

14. Miyamoto Y, Fujisawa K, Takechi M, Momota Y, Yuasa $\mathrm{T}$, Tatehara $\mathrm{S}$, et al. Effect of the additional installation of implants in the posterior region on the prognosis of treatment in the edentulous mandibular jaw. Clin Oral Implants Res. 2003;14:727-33.

15. Komiyama Y. The interface between surgery and prosthodontics in implant dentistry Proceedings of the Third International Congress on Tissue Integration in Oral and Maxillofacial Reconstruction, Nagoya, Japan. 1996:45-9.

16. Tang L, Lund JP, Tache R, Clokie CM, Feine JS. A withinsubject comparison of mandibular long-bar and hybrid implant-supported prostheses: psychometric evaluation and patient preference. J Dent Res. 1997;76:1675-83.

17. ELsyad MA, Elsaadawy MG, Abdou AM, Habib AA. Effect of different implant positions on strain developed around four implants supporting a mandibular overdenture with rigid telescopic copings. Quintessence Int. 2013;44:679-86.

18. Caruso G, Cattaneo A. Removable prosthesis supported by implants according to the Cagliari modified conometry technique: case report. Int J Periodontics Restorative Dent. 2007;27:259-65.

19. Moll D, Yildirim M, Spiekermann H, Wolfart S. Telescopic crown-retained removable partial dentures on teeth and implants: An 8- to 9-year prospective randomized clinical trial. Clin Oral Implants Res. 2012.

20. Heckmann SM, Winter W, Meyer M, Weber HP, Wichmann MG. Overdenture attachment selection and the loading of implant and denture-bearing area. Part 2: A methodical study using five types of attachment. Clin Oral Implants Res. 2001;12:640-7.
21. Heckmann SM, Winter W, Meyer M, Weber HP, Wichmann MG. Overdenture attachment selection and the loading of implant and denture-bearing area. Part 1: In vivo verification of stereolithographic model. Clin Oral Implants Res. 2001;12:617-23.

22. Heckmann SM, Schrott A, Graef F, Wichmann MG, Weber HP. Mandibular two-implant telescopic overdentures. Clin Oral Implants Res. 2004;15:560-9.

23. Eitner S, Schlegel A, Emeka N, Holst S, Will J, Hamel J. Comparing bar and double-crown attachments in implantretained prosthetic reconstruction: a follow-up investigation. Clin Oral Implants Res. 2008;19:530-7.

24. Hoffmann O, Beaumont C, Tatakis DN, Zafiropoulos GG. Telescopic crowns as attachments for implant supported restorations: a case series. J Oral Implantol. 2006;32:291-9.

25. Misch CE. The edentulous mandible: An Organized approach to implant supported overdentures In Contemporary implant dentistry: Misch CE, Abbas HA, eds Dental implant prosthetics. 3nd ed St Louis: Mosby 2008:P.293313.

26. Besimo CH, Graber G, Fluhler M. Retention force changes in implant-supported titanium telescope crowns over longterm use in vitro. J Oral Rehabil. 1996;23:372-8.

27. Ohkawa S, Okane H, Nagasawa T, Tsuru H. Changes in retention of various telescope crown assemblies over longterm use. J Prosthet Dent. 1990;64:153-8.

28. Weigl P, Hahn L, Lauer HC. Advanced biomaterials used for a new telescopic retainer for removable dentures: Ceramic vs. Electroplated Gold Copings:

Part I. In Vitro Tribology Effects. J Biomed Mater Res. 2000;53:320-36.

29. Elsyad MA, Khirallah AS. Circumferential bone loss around splinted and nonsplinted immediately loaded implants retaining mandibular overdentures: A randomized controlled clinical trial using cone beam computed tomography. J Prosthet Dent. 2016;116 741-8

30. Naitoh M, Hayashi H, Tsukamoto N, Ariji E. Labial bone assessment surrounding dental implant using cone-beam computed tomography: an in vitro study. Clin Oral Implants Res. 2012;23:970-4.

31. Raes F, Renckens L, Aps J, Cosyn J, De Bruyn H. Reliability of circumferential bone level assessment around single implants in healed ridges and extraction sockets using cone beam CT. Clin Implant Dent Relat Res. 2013;15:661-72. 
32. Razavi T, Palmer RM, Davies J, Wilson R, Palmer PJ. Accuracy of measuring the cortical bone thickness adjacent to dental implants using cone beam computed tomography. Clin Oral Implants Res. 2010;21:718-25.

33. Shiratori LN, Marotti J, Yamanouchi J, Chilvarquer I, Contin I, Tortamano-Neto P. Measurement of buccal bone volume of dental implants by means of cone-beam computed tomography. Clin Oral Implants Res. 2012;23:797-804.

34. Krennmair G, Suto D, Seemann R, Piehslinger E. Removable four implant-supported mandibular overdentures rigidly retained with telescopic crowns or milled bars: a 3-year prospective study. Clin Oral Implants Res. 2012;23:481-8.

35. Tokuhisa M, Matsushita Y, Koyano K. In vitro study of a mandibular implant overdenture retained with ball, magnet, or bar attachments: comparison of load transfer and denture stability. Int J Prosthodont. 2003;16:128-34.
36. Albrektsson T, Zarb G, Worthington P, Eriksson AR. The long-term efficacy of currently used dental implants: a review and proposed criteria of success. Int J Oral Maxillofac Implants. 1986;1:11-25.

37. Adell R, Lekholm U, Rockler B, Branemark PI. A 15-year study of osseointegrated implants in the treatment of the edentulous jaw. Int J Oral Surg. 1981;10:387-416.

38. Ying Z, Gonda T, Maeda Y. Influence of Attachment Height and Shape on Lateral Force Transmission in Implant Overdenture Treatment. Int J Prosthodont. 2017;30:586-91.

39. de Las Casas EB, de Almeida AF, Cimini Junior CA, Gomes Pde T, Cornacchia TP, Saffar JM. Determination of tangential and normal components of oral forces. J Appl Oral Sci. 2007;15:70-6. 